\title{
Zebrafish: Model for the study of inflammation and the innate immune response to infectious diseases
}

\section{Beatriz Novoa and Antonio Figueras*}

Instituto de Investigaciones Marinas, CSIC. Eduardo Cabello 6, 36208 Vigo, Spain.

*Corresponding author: antoniofigueras@iim.csic.es

\begin{abstract}
The zebrafish (Danio rerio) has been extensively used in biomedical research as a model to study vertebrate development and hematopoiesis and recently, it has been adopted into varied fields including immunology. After fertilization, larvae survive with only the innate immune reponses because adaptive immune system is morphologically and functionally mature only after 4-6 weeks post fertilization. This temporal separation provides a suitable system to study the vertebrate innate immune response in vivo, independently from the adaptive immune response. The transparency of early life stages allows a useful real-time visualization. Adult zebrafish which have complete (innate and adaptative) immune systems offer also advantages over other vertebrate infection models: small size, relatively rapid life cycle, ease of breeding and a growing list of molecular tools for the study of infectious diseases. In this review, we have tried to give some examples of the potential of zebrafish as a valuable model in innate immunity and inflammation studies.
\end{abstract}




\section{Introduction}

The zebrafish (Danio rerio) has been extensively used to study vertebrate development and hematopoiesis but interest in this model organism has gradually expanded in recent years into the fields of human disease, cancer and immunology (Dooley and Zon 2000; Trede et al. 2001, 2004; Yoder et al. 2002; Traver et al. 2003; Stern and Zon 2003; de Jong and Zon 2005; Langenau and Zon 2005; Sullivan and Kim 2008). Concerning immunology and infectious diseases research, interestingly, there is a clear temporal separation between both innate and adaptive immune responses in zebrafish. Only the innate immune system is present until several weeks after fertilization; larvae must survive until that time solely on the strength of their innate immune system. The innate immune system is detectable and active at day 1 of zebrafish embryogenesis (Herbomel et al. 1999, 2001), whereas the adaptive immune system is morphologically and functionally mature only 4-6 weeks after the fertilization of the egg (weeks postfertilization, wpf) when the lymphocytes become functional (Willett et al. 1999; Davidson and Zon 2004; Trede et al. 2004; Lieschke and Currie 2007). This temporal separation provides a suitable system to study the vertebrate innate immune response in vivo, independently from the adaptive immune response (Stockhammer et al. 2009). The transparency of early life stages is another advantage that allows useful real-time visualization. Moreover, adult zebrafish which have complete (innate and adaptative) immune systems, may have certain advantages over other vertebrate infection models such as mice: their small size, relatively rapid life cycle and ease of breeding permit a large number of genetic screens to be performed.

Like those of amphibians, fish immune systems present almost the full repertoire of lymphoid organs and immune cell types found in mammals (Trede et al. 2004; Zapata et al. 2006). However, unlike that of mammals, fish development occurs in an open environment. Therefore, the immune system may be exposed early to a large number of pathogens. Zebrafish larvae hatch 2-3 days after fertilization, suggesting that their immune system must develop quickly to produce a heterogeneous immune repertoire (Du Pasquier et al. 2000; Poorten and Kuhn 2009). 
Yoder et al. (2002) have pointed out that the zebrafish can be employed as a new immunological model system. However, these authors also enunciate a key question "what will studies using this species offer that cannot be realized using other models?" Trede et al. (2004) have discussed the advent of the zebrafish as a powerful vertebrate model organism that may have an impact on immunological research based on the important role that innate immunity plays in orchestrating immune responses. The review by Traver et al. (2003) provides an overview of the value and potential of zebrafish as a model organism to study the development and function of the immune system. These authors propose to "use the zebrafish as a model organism for immunology as an alternative to study humans or mice". Fish are phylogenetically lower vertebrates and rely more than mammals on innate immune mechanisms. The use of the whole animal in studies that utilize zebrafish can complement research on components of immunity that is based on in vitro experiments utilizing isolated or cultured cells (which are very useful for understanding specific pathways but may not reflect the cellular interactions that occur in the whole animal).

In this article we have tried to sumarize advantages that zebrafish can offer for immunological research.

\section{Main cells involved in the innate immune response in zebrafish}

Zebrafish leukocytes, even in embryos, function in host defense. By direct microscopy, it is possible to observe that neutrophils rapidly accumulate at wounds (Lieschke et al. 2001; Renshaw et al. 2006) and bacterial foci (Le Guyader et al. 2008) and that primitive macrophages also phagocytose particles and bacteria (Herbomel et al. 1999; Lieschke et al. 2001; Hall et al. 2007). Although recent studies have reported the presence of eosinophils and mast cells in zebrafish (Bertrand et al. 2007; Dobson et al. 2008; Balla et al. 2010), larvae innate immune system comprises primarily of neutrophils and macrophages. Neutrophils are the first to respond to an injury; macrophages are subsequently recruited to inflamed tissues to phagocytose pathogens and tissue debris. 
Neutrophils: Zebrafish possess cells analogous to neutrophils in adults and larvae. Neutrophils rapidly accumulate at wounds (Renshaw et al. 2006) and this chemotactic activity is critical in responding to tissue injury and infections (Fig. 1). Today, a range of tools for labeling neutrophils has been developed in zebrafish using transgenic lines such as the zMPO:GFP which expresses GFP under the control of the myeloperoxidase promoter (Renshaw et al. 2006; Mathias et al. 2006) and the transgenic line CLGY463 which has an enhancer detection insertion near a novel myc transcription factor (Meijer et al. 2008). Moreover, Anne Huttenlocher and colleagues have identified mutants with increased neutrophil numbers. The first such mutant, in the Hail gene, results in damage to the epithelium and is associated with increased neutrophil retention at the site of an epithelial injury (Mathias et al. 2007). The second, in the Fad24 gene, leads to muscle damage and is also associated with increased tissue neutrophilia (Walters et al. 2009).

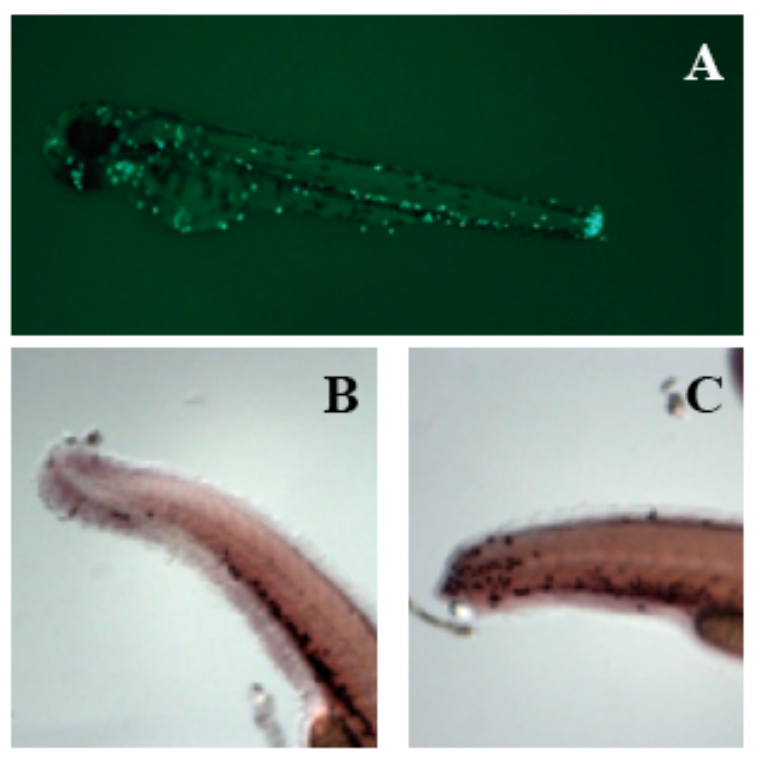

Fig. 1 Migration of zebrafish neutrophils to the injury site at the tail. Figure 1a shows transgenic fish (Renshaw et al. 2006) expressing GFP under the control of the myeloperoxidase promoter with a cut in the tail. Panel $\mathbf{b}$ (normal fish) and $\mathbf{c}$ (fish with a cut in the tail) correspond to a whole mount in situ hybridization of zebrafish embryos using a myeloperoxidase probe which also labels neutrophils. 
These tools permit real-time visualization of the response of neutrophils to inflammation and infections making it possible to visualize the neutrophil migration in three-dimensional (3D) tissue environments in vivo (Yoo et al. 2010). Until now, these studies were difficult to accomplish because few systems were available to permit highresolution imaging of the signaling dynamics in living cells within multicellular organisms. Zebrafish are also being used to understand the mechanisms that regulate the resolution phase of the inflammatory response. One of these mechanisms is the regulation of apoptosis (Haslett 1999) which is being studied in zebrafish by using pan-caspase inhibitors and by blocking or overexpressing candidate regulators of apoptosis (Renshaw et al. 2007). Moreover, in vivo time-lapse imaging has been used to demonstrate that neutrophils subsequently display directed retrograde chemotaxis back toward the vasculature. These findings implicate retrograde chemotaxis as a novel alternative mechanism that regulates the resolution phase of the inflammatory response (Mathias et al. 2006).

Macrophages: Although several genes have been suggested as markers for the monocyte/macrophage lineage in zebrafish, including 1-plastin and lysozyme C (Herbomel et al. 1999; Liu and Wen 2002), subsequent studies have indicated that these genes can also be expressed in other leukocytes ( $\mathrm{Su}$ et al. 2007; Meijer et al. 2008). Only CSF1R or c-fms has become an accepted marker for zebrafish macrophages (Herbomel et al. 2001). Phagocytically active macrophages are the first leukocytes to appear in the zebrafish embryo (Herbomel et al. 1999; Lieschke et al. 2002) and exhibit avid motility and phagocytosis of cellular debris and bacteria (Herbomel et al. 1999; Redd et al. 2006). Several different subsets of the macrophage/monocyte lineage have been described, including those recently described as "inflammatory macrophages" which are involved in the inflammatory response to wounding in zebrafish larvae (Mathias et al. 2009). Recently, a macrophage-specific marker has been identified (mpegl) and its promoter has been used in mpegl-driven transgenes. Using these lines, researchers have followed the different behavior of neutrophils and macrophages after wounding (Ellett et al. 2010). 


\section{Immune genes characterized in zebrafish}

An important requirement to use the zebrafish as a model to study human immunity (Trede et al. 2004) is the knowledge of the genes that encode components of the mammalian immune system that are also found in fish (Purcell et al. 2006). This knowledge would also aid our understanding of the evolution of immunity. We must also consider that a whole genome duplication occurred early in the teleost lineage. It has been proposed that the availability of additional gene copies facilitated the evolution of the highly diverse morphology and behavior of teleost fish (Venkatesh 2003; Volff 2005).

Many protein and gene families involved in innate immune mechanisms have been described in zebrafish, suggesting that many components of the innate immune signaling pathways known from mammals are conserved in teleost fish. Stein et al. (2007) have searched the fish genomes for genes encoding components of the immune system. Although most of the components known in mammals have clearly recognizable orthologous in fish, class II cytokines and their receptors have diverged extensively, obscuring their orthologies. In the opinion of Stein and colleages, the main innate immune signaling pathways (kinases, adaptors in the TLR signaling pathway, interferon response factors, signal transducers and activators of transcription) are conserved in teleost fish. Whereas the components that act downstream of the receptors are highly conserved, components that are known or assumed to interact with pathogens are more divergent. These observations agree with those of Carradice and Lieschke (2008) who have reported that zebrafish intracellular cytokine signaling pathways are more conserved overall than their ligands and receptors.

Aggad et al. (2010) have studied the conditions under which Ifn- $\gamma$ is induced in fish larvae and adults and have also identified also the receptors for class II helical cytokines (IFNs and Il-10 and its related cytokines). Infection studies using two different pathogens have shown that IFN-gamma signalling is required for resistance to bacterial infections in the young embryo (Sieger et al. 2009).

Concerning to the complement system, C3, C4 and factors $\mathrm{B}$ and $\mathrm{H}$ have been identified to date in zebrafish (Sun et al. 2010). It has been shown that complement 
components such as $\mathrm{C} 3$ and $\mathrm{Bf}$ can be transferred from mother to offspring and play a protective role in developing embryos. Their expression increases in zebrafish embryos and larvae in response to lipopolysaccharide (LPS) (Wang et al. 2008a, b; 2009). Multiple copies of mannose binding lectin (MBL) which is involved in the activation of the lectin pathway of the complement system, have been detected in zebrafish. Polymorphisms within MBL may be critical in determining fish susceptibility or resistance to various pathogenic organisms, as has been reported in humans (Jackson et al. 2007).

Other genes related to the immune response have been described in zebrafish. Yoder et al. (2001) have described a highly diverse, multigene family of novel immune-type receptor (NITR) genes in zebrafish. These genes are predicted to encode type I transmembrane glycoproteins which consist of extracellular variable (V) and V-like C2 (V C2) domains, a transmembrane region and a cytoplasmic tail. All of the genes examined encode immunoreceptor tyrosine-based inhibition motifs in the cytoplasmic tail. NITRs have been proposed to be "functional orthologs" of mammalian natural killer receptors (NKRs) (Yoder 2009).

Antimicrobial peptides (Zou et al. 2007) and peptidoglycan recognition proteins (PGRPs) with peptidoglycan-lytic amidase activity and a broad spectrum of bactericidal activity (Li et al. 2007; Chang et al. 2007) have also been identified in zebrafish.

Zebrafish have been investigated for the presence of Toll-like receptor (TLR) proteins which function as sentinels against infection, participating in the earliest innate immune responses. Purcell et al. (2006) have characterized the key components of the TLRsignaling pathway, including MYD88, TIRAP, TRIF, TRAF6, IRF3 and IRF7 in zebrafish. It has also been reported that the main receptor for LPS, the TLR4, is expressed in zebrafish during early stages of infection (Meijer et al. 2004; Jault et al. 2004). However, zebrafish appear to respond to LPS through a mechanism that is independent of the mammalian TLR4-MD2 LPS receptor complexes. Zebrafish TLR4 fails to respond to LPS due to differences in its extracellular domains (Sepulcre et al. 2009; Sullivan et al. 2009). The zebrafish genes $t l r 4 a$ and $t l r 4 b$ appear to be paralogous rather than orthologous to human TLR4 but they probably play a role in zebrafish immunity, supporting the hypothesis that alternative LPS induction pathways predominate in fishes (Sullivan et al. 2009). 


\section{Functional ontogeny of the immune system}

Excellent studies have been performed on the ontogeny of the lymphoid system during the embryonic period of the zebrafish (Willet et al. 1997; 1999; Trede and Zon 1998; Trede et al. 2001), but little is known about the maturation of its immune system with regard to form and function, which occurs later in development. Lam et al. (2004) have observed a humoral response to T-independent antigen (formalin-killed Aeromonas hydrophila) and T-dependent antigen (human gamma globulin) in immunized zebrafish at 4 and 6 weeks post fertilization (wpf), respectively, indicating that immunocompetence had been achieved. The findings confirm previous studies that have reported that the zebrafish adaptive immune system is morphologically and functionally mature by $4-6 \mathrm{wpf}$. The function of the embryonic zebrafish immune system before maturation has not been addressed in detail. Dios et al. (2010) have investigated the expression levels of several antiviral and inflammatory genes (IL-1 $\beta$, iNOS, TNF- $\alpha$, TLR3, IFN-I, IFN $\gamma$, IRF3, MDA-5, Mx) both constitutively and after viral stimulation during early development. Most of the genes involved in the antiviral response reached a positive reaction threshold as early as 5 days post fertilization (dpf). This finding is not surprising because oviparity requires a rapid development of the immune system. The same authors have determined how the expression of these genes is affected by changes in the temperature. Whereas the expression of most of the antiviral genes was almost completely inhibited at $15^{\circ} \mathrm{C}$, inflammatory genes such as IL- $1 \beta$, iNOS and TNF- $\alpha$ showed not obvious differences between 15 and $28^{\circ} \mathrm{C}$. After treatment with poly I:C (which mimics a viral infection), larvae showed significant differences in the gene expression, especially for of the interferon-induced protein Mx. In adults, however, poly I:C treatment led to a smaller increase in gene expression compared to larval Mx levels. Thus, $\mathrm{Mx}$ apparently plays an important role in viral immunity in larvae, in which the adaptive immune response is not fully functional. 


\section{Zebrafish as a model for infectious diseases}

Sullivan and Kim (2008) have published a comprehensive review of the capabilities and potential of the zebrafish model system with an overview of information on zebrafish infectious disease models. The advantages of the zebrafish system are particularly relevant during the embryonic and larval stages (Fig. 2) and are very useful in the study of hostmicrobe interactions (Kanther and Rawls 2010).
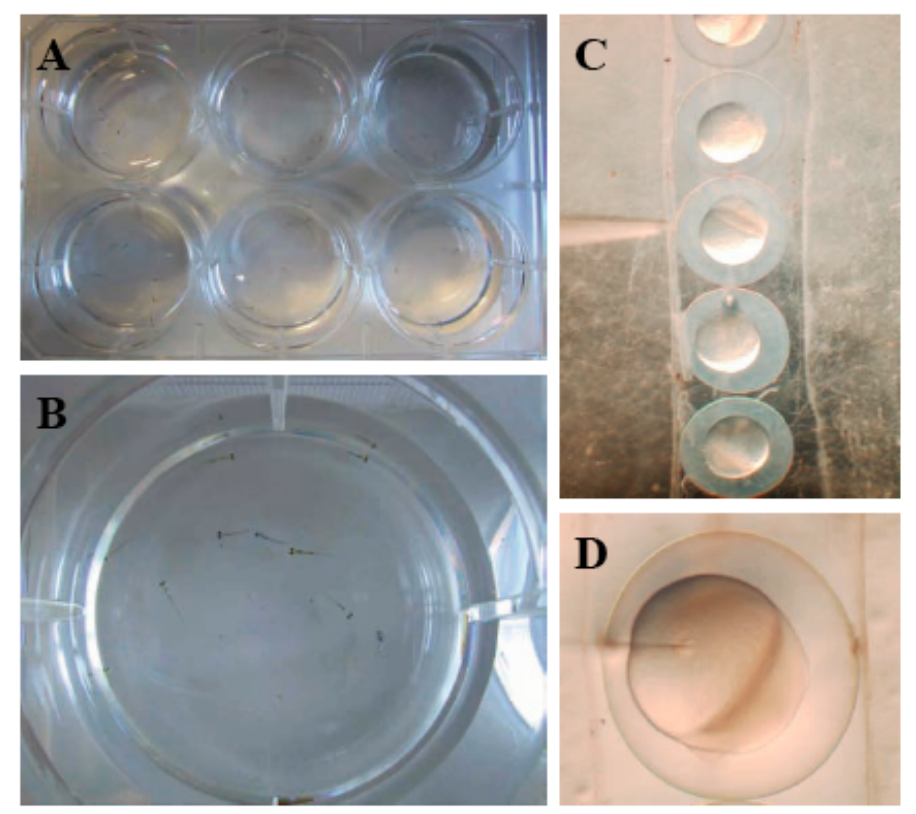

Fig. 2 Zebrafish embryos and larvae are useful to study innate immune functions and interaction with pathogens, numbers of animals can be high in a reduced space. Panel a. A multiwell plate where it is possible to conduct experimental infections with zebrafish larvae. Panel $\mathbf{b}$ shows one of the wells at higher magnification in which the larvae can be seen. Figures $\mathbf{2 c}$ and $\mathbf{2 d}$ describe the microinjection of zebrafish embryos.

Viral diseases. The zebrafish has been proposed and used as a laboratory model fish species to study fish viral diseases. To date, most studies of viral infections in zebrafish have been related to viruses affecting aquacultured fish (Fig. 3). Vaccine and treatment trials, which are 
sometimes highly expensive to perform with commercial species, can be conducted at a reduced cost using this model.
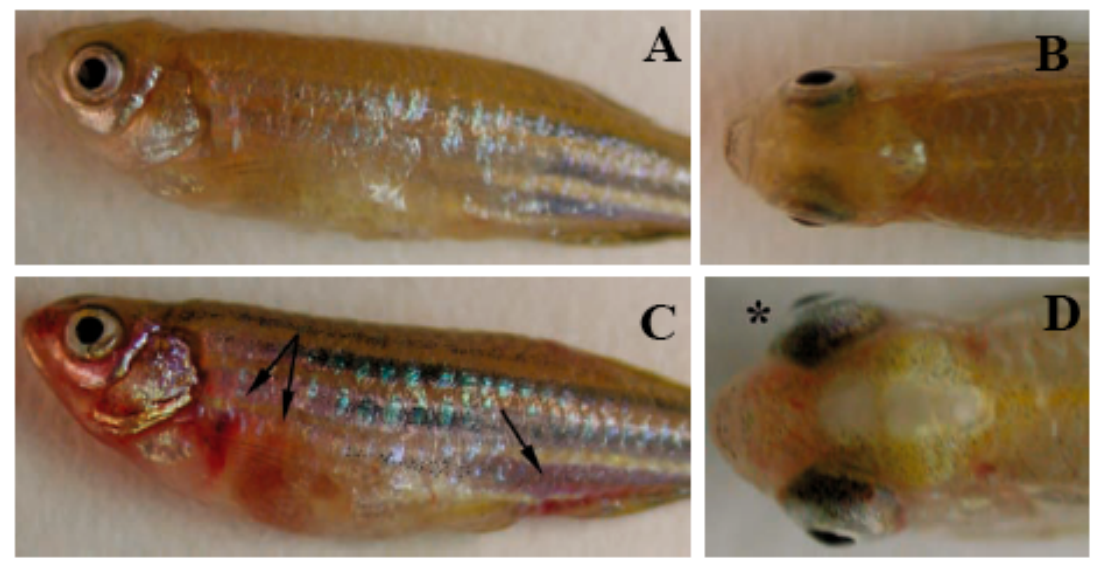

Fig. 3 Aspect of the external clinical signs of adult zebrafish infected with viral hemorrhagic septicemia virus (VHSV), a serious rhabdovirus caused disease affecting aquacultured fish. Panels a and b show uninfected fish and panels $\mathbf{c}$ and $\mathbf{d}$ correspond to infected fish with the characteristic symptoms of the disease: hemorrhages (arrows), exophthalmia (*) and a distended visceral cavity.

La Patra et al. (2000) have infected hematopoietic precursors from the zebrafish, with the rhabdovirus infectious hematopoietic necrosis virus (IHNV) and the birnavirus infectious pancreatic necrosis virus (IPNV). Infection of whole fish with viral supernatants demonstrated infectious replicants for both viruses, indicating that the virus host range includes the zebrafish. In other species, infection with these viruses leads to prominent hematopoietic necrosis of the head kidney, the major site of adult hematopoiesis. The kinetics of hematopoietic defects differed between IHNV and IPNV infection; however, fish infected with either virus recovered by 6 days postinfection. Other experimental infections have been conducted with other rhabdoviruses, for example, Sanders et al. (2003) have shown that zebrafish are susceptible to another rhabdovirus adapted to higher temperatures, spring viremia of carp virus (SVCV). Mortality exceeded 50\% in fish exposed to the virus, which exhibited epidermal petechial hemorrhages followed by death. Histological lesions included multifocal brachial necrosis and melanomacrophage proliferation in the gills, liver 
and kidneys. López-Muñoz et al. (2010) have also found that zebrafish larvae are unable to mount a protective antiviral response to waterborne SVCV. Nevertheless, zebrafish larvae appear to possess a functional antiviral system since ectopic expression of the cDNA of both groups I and II IFN was able to protect them against SVCV via the induction of IFNstimulated genes (ISGs).

Novoa et al. (2006) have proposed to use zebrafish as a model to study vaccination against viral hemorrhagic septicemia virus (VHSV) (Fig. 3). Even at low temperatures, fish were protected by a vaccine generated by reverse genetics against the virulent virus.

Lu et al. (2008) have successfully infected zebrafish with a nodavirus, nervous necrosis virus (NNV) that induces high mortalities in the larval and juvenile stages of infected marine fish. The disease caused by this virus is characterized by lethargy, abnormal spiral swimming, loss of equilibrium and neurological lesions characterized by cellular vacuolisation and neuronal degeneration mainly in the brain, retina, spinal cord and ganglia of the affected fish. In zebrafish, infected animals exhibited typical NNV symptoms, showing brain lesions similar to those observed in natural hosts.

Fungal diseases. Chao et al. (2010) have developed a zebrafish model for Candida albicans infections. They have shown that $C$. albicans can colonize and invade zebrafish at multiple anatomical sites and can kill the fish in a dose-dependent manner. They monitored the progression of the C. albicans yeast-to-hypha transition, the gene expression of the pathogen and the early host immune response. Experimental infections with different C. albicans strains were conducted to determine each strain's virulence, and the results were similar to findings reported in previous mouse model studies. Using zebrafish embryos, the interaction between pathogen and host myelomonocytic cells can be visualized in vivo. Chao et al. (2010) conclude that zebrafish are a useful model host to study C. albicans pathogenesis and other invasive fungal research.

Bacterial diseases. A number of studies on bacterial diseases have been conducted using zebrafish. For instance, Streptococcus iniae, which causes a systemic invasive infection in fish resembles human infections by several streptococcal species (Neely et al. 2002; Van der 
Sar et al. 2004; Phelps et al. 2009). Kizy and Neely (2009) have determined the role of several Streptococcus pyogenes virulence genes using zebrafish as a host.

Zebrafish infection with Mycobacterium marinum has been proposed as a model for tuberculosis (Davis et al. 2002). Swaim et al. (2006) have shown that zebrafish are naturally susceptible to Mycobacterium marinum, a close genetic relative of the causative agent of human tuberculosis, Mycobacterium tuberculosis. They have also developed a zebrafish embryo-M. marinum infection model to study host-pathogen interactions in the context of innate immunity. Zebrafish tuberculous granulomas undergo caseous necrosis, similar to human tuberculous granulomas. In contrast to mammalian tuberculous granulomas, zebrafish lesions contain few lymphocytes, calling into question the role of adaptive immunity in fish tuberculosis. However, like ragl mutant mice infected with $M$. tuberculosis, they found that rag1 mutant zebrafish are hypersusceptible to M. marinum infection, demonstrating that the control of fish tuberculosis is dependent on adaptive immunity.

Lin et al. (2007) have studied the zebrafish immune response to infections with Aeromonas salmonicida and Staphylococcus aureus, a Gram-negative and a Gram-positive bacteria. Many of the identified genes induced upon infection (IL-1, fibrinogen, haptoglobin, complement components and hepcidin) are related to the acute phase proteins (APPs), with induction patterns similar to those observed in mammals. This observation implies evolutionarily conserved mechanisms among fish and mammals. Lin et al. (2007) also discovered some novel APPs, suggesting different immune strategies adopted by fish species. Notably, LECT2 was induced by up to 1000-fold upon infection, shedding new light on the function of this gene.

Rodriguez et al. (2008) have reproduced Aeromonas hydrophyla disease symptoms similar to those present in humans and mortality in fish after experimental infection by intraperitoneal injection or by immersing wounded fish (Fig. 4). Fish showed clinical symptoms such as hemorrhaging and abdominal swelling. However histological lesions were not observed perhaps because the peracute form of the disease killed the fish before any changes could become evident. 
Vojtech et al. (2009) have established a zebrafish/Francisella (a highly virulent and infectious pathogen) model of pathogenesis and host immune response. Adult zebrafish are susceptible to acute Francisella-induced disease and suffer mortality in a dose-dependent manner. Zebrafish mount a significant tissue-specific proinflammatory response to infection, as measured by the upregulation of IL-1, interferon gamma and TNF mRNA beginning by 6 $\mathrm{h}$ postinfection and persisting for up to 7 days postinfection.

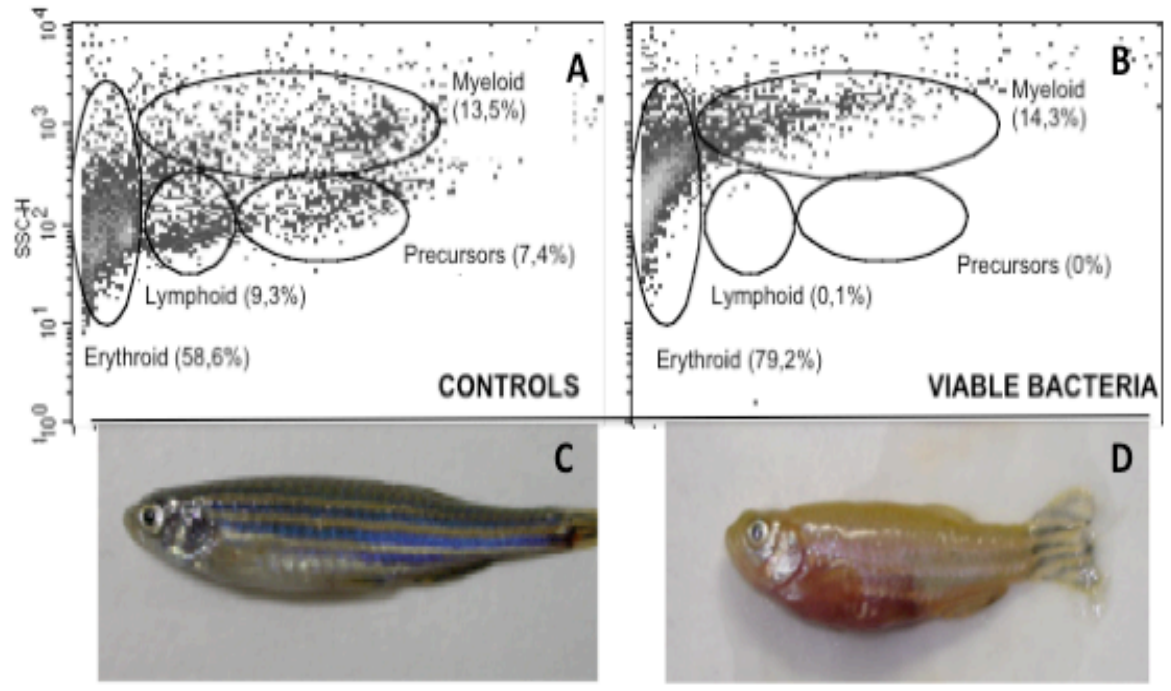

Fig. 4 Adult zebrafish were susceptible to the Aeromonas hydrophila infection. Flow cytometry of zebrafish kidney cell populations analyzed by size (forward scatter; FSC) and granularity (side scatter; SSC) shows important changes after infection related with the hemolytic activity of Aeromonas: the kidney cells treated with viable bacteria showed a drop in the populations of lymphoid cells and precursor immature cells (b) compared with uninfected cells (a). Figures $4 \mathbf{c}$ and $4 \mathbf{d}$ show the aspect of control fish or infected fish with symptoms characterized by a distended visceral cavity and abdominal hemorrhages.

Infections with Salmonella typhimurium and Vibrio anguillarum have also been conducted in zebrafish (Van der Sar et al. 2003; O'Toole et al. 2004). To characterize the embryonic innate host response at the transcriptome level against Salmonella, which causes 
a lethal inflammatory infection in zebrafish embryos, Ordas et al. (2010) have extended and validated previous microarray data through Illumina next-generation sequencing analysis. Their report describes infection-responsive genes in zebrafish embryos, which include genes encoding transcription factors, signal transduction proteins, cytokines and chemokines, complement factors, proteins involved in apoptosis and proteolysis, proteins with antimicrobial activities and many known or novel proteins not previously linked to the immune response.

\section{Application of genomics, transgenesis and other tools in the study of infectious diseases}

Powerful genetic approaches can be conducted in zebrafish to ascertain the roles that particular genes play in disease resistance.

\subsection{Mutagenesis}

One of the main advantages of the zebrafish is the ability to easily perform forward genetic screens (Streisinger et al. 1981; Solnica-Krezel et al. 1994; Knapik 2000). Target induced local lesions in genomes (TILLING) methodology is being employed routinely to generate "knockout" zebrafish (Deiters and Yoder, 2006). Together with several mutants described above, one of the most interesting examples of the application of these techniques to immunological research is the disruption of the ragl gene by an ENU-induced point mutation that creates a

premature stop codon in the $\operatorname{rag} 1^{t 26683}$ allele thus encoding a truncated Rag1 protein (Wienholds et al. 2002). Although homozygous fish ( $\mathrm{ragl}^{-/}$) are more susceptible to an injected dose of Mycobacterium marinum and their immunoglobulin genes fail to undergo V(D)J recombination, they are able to reach adulthood and are fertile. Jima et al. (2009) have hypothesized that ragl-/- zebrafish may possess an enhanced innate immune response to compensate for the lack of an adaptive immune system. Using microarrays these authors have compared the expression profiles of rag1 deficient zebrafish and controls. The majority of the differences between wild type and mutant zebrafish were found in the intestine, where ragl-/- 
fish exhibited an increased expression of innate immune genes, including those of the coagulation and complement pathways. Petrie-Hanson et al. (2009) have shown that in comparison to wild-type zebrafish, ragl mutants have a significantly reduced lymphocyte-like cell population (lacking functional $\mathrm{T}$ and $\mathrm{B}$ lymphocytes) but have a similar macrophage/monocyte population and a significantly increased neutrophil population. These zebrafish have leukocyte populations comparable to those of severe combined immunodeficient (SCID) and rag 1 and/or 2 mutant mice.

Although the development of zebrafish model systems for many medical problems is in its early stages, large-scale genetic screening programs have been successfully applied to blood research and other developmental problems (Patton and Zon 2001). Today, these methods are being used for several diseases, including epilepsy (Hortopan et al. 2010).

\subsection{Microarrays and next- generation sequencing methods}

Van der Saar et al. (2009) have conducted microarray studies to analyze the transcriptome responses of zebrafish to two Mycobacterium marinum strains that produce distinct disease outcomes (acute disease with early lethality or chronic disease with granuloma formation). The transcriptome profiles involved in acute versus chronic infections and in embryonic versus adult infected fish partially overlapped, even though the strains induce profoundly different disease phenotypes. The strongest differences were observed at the initial stage of the disease. Stockhammer et al. (2009) have used microarrays to perform a time-course transcriptome profiling study and gene ontology analysis of the embryonic innate immune response to infection by two Salmonella strains that elicit either a lethal infection or an attenuated response. These authors have confirmed a conservation of the host responses similar to that detected in other vertebrate models.

$\mathrm{Wu}$ et al. (2010) have used a commercial zebrafish microarray to identify alterations in gene expression in zebrafish injected with Streptococcus suis, an important pathogen in swine. At least 189 genes showed differential expression.

The immune response of zebrafish has been studied not only using microarrays but also using Solexa/Illumina's digital gene expression (DGE) system, a tag-based transcriptome sequencing method. This method has been used to investigate the changes in 
zebrafish transcriptome profiles induced by Mycobacterium and Salmonella (Hegedus et al. 2009; Ordas et al. 2010).

\subsection{Transgenesis and RNAi}

Morpholino-modified antisense oligonucleotides ('morpholinos') are routinely used in zebrafish to transiently block genes and reduce protein expression. Levraud et al. (2008) have provided a protocol to generate zebrafish embryos deficient in a protein of interest for innate immune signaling using antisense morpholino oligonucleotides.

Chang and Nie (2008) have used RNA interference (siRNA) and real time quantitative PCR to explore the effect of zebrafish peptidoglycan recognition protein 6 (zfPGRP6) on the Toll-like receptor signaling pathway. The expression of beta-defensin-1 was downregulated in embryos silenced by zfPGRP6. In challenge experiments to determine the anti-bacterial response to Gram-negative bacteria, RNAi knock-down of zfPGRP6 markedly increased susceptibility to Flavobacterium columnare. Aggad et al. (2010) have used morpholino-mediated loss-of-function analyses to screen candidate receptors and identify the components of their receptor complexes. They found that Ifn- $\gamma 1$ and Ifn- $\gamma 2$ bind to different receptor complexes.

Overexpression of a protein of interest is another strategy to investigate gene functions. In some cases, zebrafish can express genes from other animals: Yazawa et al. (2006) have established a transgenic zebrafish strain expressing a chicken lysozyme gene under the control of the Japanese flounder keratin gene promoter and have investigated its resistance to a pathogenic bacterial infection. In a challenge experiment, $65 \%$ of the F2 transgenic fish survived an infection of Flavobacterium columnare, and 60\% survived an infection of Edwardsiella tarda, whereas $100 \%$ of the control fish were killed by both pathogens. Hsieh et al. (2010) have also overexpressed tilapia hepcidin in zebrafish reporting that transgenic fish showed significantly higher bacterial clearance after Vibrio vulnificus challenge but not after Streptococcus agalactiae challenge. Transgenic zebrafish showed increased endogenous expression of Myd88, tumor necrosis factor-alpha, and TRAM1 in vivo. Peng et al. (2010) have produced antimicrobial peptide epinecidin-1 transgenic zebrafish, which are able to effectively inhibit bacterial growth. 
Transgenesis can also be conducted by linking green fluorescent protein (GFP) to genes or promoters of interest, making it possible to visualize processes that would otherwise be difficult to observe.

An extensive database of transgenic and mutant zebrafish lines is available at the Zfin web page (http://zfin.org/cgi-bin/webdriver?MIval=aa-ZDB home.apg).

\subsection{Chemical genetic screens}

Zebrafish can be used in a 'whole animal'-based compound discovery strategy that represents an advance if it is compared to traditional biochemical drug discovery programs. The use of larval zebrafish facilitates rapid and inexpensive in vivo vertebrate analysis. Phenotypic screens have been successfully employed to identify compounds as candidate drugs for many different conditions (Zon and Peterson 2005; Lieschke and Currie 2007; Bowman and Zon 2010). Whereas traditional approaches look for in vitro inhibitors of a particular target, this approach involves a physiological process (for example, inflammation resolution) and looks for compounds that accelerate that process (Martin and Renshaw 2009). Phenotype-based small molecule screening in zebrafish has been described in several studies (Moon et al. 2002) and is now being applied to Alzheimer's disease (Arslanova et al. 2010), hematopoiesis (Paik et al. 2010), multiple sclerosis (Buckley et al. 2010), glucocorticoid resistance (Schoonheim et al. 2010), cancer angiogenesis (Wang et al. 2010) and cardiovascular diseases (Xu et al. 2010).

\subsection{Imaging}

As discussed above, one of the main advantages of the zebrafish is the ease of phenotypic analysis. The zebrafish embryo is optically transparent, making it possible to detect functional and morphological changes in internal organs without having to kill or dissect the organism. These functional and morphological changes can be further emphasized by the use of transgenic lines and reporter molecules (Zon and Peterson 2005). These characteristics of the zebrafish have made it possible to assess various aspects of the immune response through microscopic observations (Levraud et al. 2008).

Lepiller et al. (2007) have shown that labeling with DAF-FM DA is an efficient method to monitor changes in NO production in live zebrafish under both physiological and 
pathophysiological conditions, suggesting applications to drug screening and molecular pharmacology. Mathias et al. (2009) and Renshaw et al. (2006) have described how the zebrafish system is suitable for both live time-lapse imaging of neutrophil chemotaxis and screening of the effects of chemical compounds on the inflammatory response in vivo.

Singer et al. (2010) have constructed a series of plasmids to label a variety of fish and human pathogens with red fluorescent protein, making it possible to observe real-time interactions between green fluorescent protein-labeled immune cells and invading bacteria in the zebrafish.

\subsection{Gnotobiotic zebrafish}

Gnotobiosis, the ability to raise animals in the absence of microorganisms is a powerful tool to study the relationships between animal hosts and their microbial residents or pathogens (Pham et al. 2008).

Rawls et al. (2004) have conducted DNA microarray comparisons of gene expression in the digestive tracts of $6 \mathrm{dpf}$ germ-free zebrafish and normal zebrafish, revealing 212 genes that are regulated by the microbiota and 59 responses that are conserved in the mouse intestine, related to the stimulation of epithelial proliferation, promotion of nutrient metabolism and innate immune responses. Colonization of germ-free zebrafish with individual members of its microbiota revealed the bacterial species specificity of selected host responses.

Using a gnotobiotic zebrafish-Pseudomonas aeruginosa model, Rawls et al. (2007) have monitored microbial movement and localization within the intestine in vivo and in real time, taking advantage of the transparency of this vertebrate species. Pseudomonads are rare members of the intestinal microbiota of healthy humans but their representation is increased in certain pathologic states, notably inflammatory bowel diseases. These studies have demonstrated the utility of gnotobiotic zebrafish in defining the molecular bases of hostmicrobial interactions in the vertebrate digestive tract. 


\section{Some examples of application to inflammatory human diseases}

As Renshaw et al. (2007) have pointed out, the use of fish to investigate medical problems could result peculiar. However, we note that major advances in medical knowledge and immunology have been obtained by studying genetic pathways in invertebrate animals such as the worm Caenorhabditis elegans and the fly Drosophila melanogaster, both of which are more distant from humans than vertebrates such as zebrafish.

Inflammatory diseases are an important cause of morbidity and mortality in various medical specialities. Below, we give some examples of human diseases that have been studied using the zebrafish as a model:

Lung disease: Unresolved neutrophilic inflammation is a major contributor to the tissue damage associated with many lung inflammatory disorders (Martin and Renshaw 2009). The resolution of inflammation depends on the termination of pro-inflammatory neutrophil functions by apoptosis. To date, the bases of neutrophil apoptosis have been studied in purified human peripheral blood neutrophils or in mice using gene manipulation techniques; however, these studies usually have limitations (Dzhagalov et al. 2007). The range of tools developed for labeling neutrophils in zebrafish can be valuable for this research. Although much more work is needed before zebrafish are widely utilized in respiratory research, studies are already being conducted because zebrafish offer complementary benefits to existing respiratory disease models (Renshaw et al. 2007). The use of zebrafish facilitates the application of pharmacological and genetic manipulations to ascertain their effects on neutrophils during inflammation, the ability to screen for novel anti-inflammatory compounds, the generation of forward and reverse genetic screens to identify regulators of the resolution of inflammation and the visualization of cell behavior in vivo.

Cardiomyopathy: Human dilated cardiomyopathy (DCM) is a myocardial disease characterized by dilatation and impaired systolic function of the ventricles. DCM is the single largest cause of heart failure and cardiac transplantation (Towbin and Bowles 2006). Accumulating evidence suggests that inflammatory and autoimmune mechanisms play a role 
in this idiopathic disease (Takeda 2003): inflammatory infiltrates and proinflammatory cytokines have been observed in DCM patients (Maisch et al. 2005). Recently, Friedrichs et al. (2009) have identified a genomic region containing genes associated with cardiac function and DCM. These authors used zebrafish to complement and confirm these studies because cardiac phenotypes could be readily assessed through direct monitoring of the heart in the living animal (Driever and Fishman 1996). Functional knockdown studies have been conducted for eight genes using morpholino (MO) antisense experiments. Knockdown of three of the genes $(H B E G F, I K$ and $S R A 1)$ resulted in impaired cardiac function phenotypes.

Septic shock: In mammals, microbial products, such as lipopolysaccharide (LPS), are potent inducers of inflammation that stimulate immune system cells after they are recognized (mainly by TLRs). In particular, Gram-negative enterobacterial LPS signals are transmitted through TLR4, whereas and Gram-positive bacteria usually activate cells in a TLR2dependent fashion, leading to the production of proinflammatory cytokines, proteases, eicosanoids, and reactive oxygen and nitrogen species (West and Heagy 2002). If this inflammatory response to infection is not tightly controlled, several pathological processes may develop, including endotoxin shock, which is a severe systemic inflammatory response characterized by fever, myocardial dysfunction, acute respiratory failure, hypotension, multiple organ failure, and often death (West and Heagy 2002; Power et al. 2004). It is well known in mammals that a previous exposure to LPS induces "endotoxin tolerance", which is thought to protect the host from endotoxic or septic shock, although the mechanisms involved are not been fully understood.

Zebrafish larvae ( $2 \mathrm{dpf}$ ) are able to produce an inflammatory response when exposed to LPS, although the minimum lethal LPS concentration is much higher than in mammals. Pseudomonas aeruginosa LPS is more lethal than E coli LPS and pretreatment with a nonlethal LPS dose induces a hypo-responsive state that protects fish subsequently exposed to the $P$. aeruginosa LPS (Novoa et al. 2009). Furthermore, two administrations of lipoteichoic acid (a component of the surface of Gram-positive bacteria) convey complete protection against exposure to a lethal concentration of LPS, demonstrating heterotolerance, as described previously in mammals (Dobrovolskaia et al. 2003). In these studies, when a 
mutant fish (Odysseus), in which CXCR4 function is inhibited, is used or when AMD3100 (a pharmacological specific CXCR4 inhibitor) was applied, the fish did not acquire tolerance to LPS. CXCR4 is a G protein-coupled chemokine receptor; these results confirm that CXCR4 belongs to the cluster involved in LPS recognition and may be involved in controlling excessive inflammatory response (Triantafilou et al. 2008).

The use of complete organisms, such as zebrafish larvae, presents an excellent opportunity to further study this model of endotoxin shock. Indeed, zebrafish have recently been used to study the WHIM syndrome, a primary immunodeficiency disorder characterized by neutropenia and recurrent infections in which CXCR4 seems to be associated with recurrent infections (Walters et al. 2010).

Intestinal inflammatory diseases: The zebrafish has emerged as a model organism for the study of host-microbe interactions related to the digestive function (Dahm and Geisler 2006; Hama et al. 2009; Kanther and Rawls 2010) because anatomical and functional conservation has been reported between the zebrafish and mammalian intestines ( $\mathrm{Ng}$ et al. 2005; Bates et al. 2007, Flores et al. 2008). Members of the microbiota influence intestinal epithelial cell proliferation rates independent of inflammation via direct modulation of $\beta$-catenin signaling (Cheesman et al. 2010). However, a breach of this intestinal host-microbe homeostasis contributes to the pathogenesis of inflammatory bowel disease (IBD), commonly manifested as Crohn's disease or ulcerative colitis (Kaser et al. 2010).

Brugman et al. (2009) have developed zebrafish model of enterocolitis to study the interactions between host intestinal cells and bacteria and to understand the pathogenesis of inflammatory bowel disease (IBD). Enterocolitis was induced by intrarectal administration of the hapten oxazolone in adult wild-type and myeloperoxidase-reporter transgenic zebrafish. Fleming et al. (2010) have developed another model of IBD in zebrafish larvae, together with a method for the rapid assessment of gut morphology and an in vivo compound screening technique. In this case, IBD was induced by the addition of 2,4,6trinitrobenzenesulfonic acid (TNBS) to the medium and changes in goblet cell number and tumor necrosis factor alpha (TNF-alpha) antibody staining were used to quantify disease severity. 
These studies affirm that zebrafish can be a powerful model suitable for mediumthroughput chemical screens in the study of gastrointestinal disease.

Other studies have been conducted to analyze the expression of genes related to these inflammatory processes in the intestine. For example, Oehlers et al. (2010a) have studied the expression gradients of antimicrobial peptide genes along the zebrafish intestine; Flores et al. (2010) have studied the zebrafish ortholog of the human DUOX1 and DUOX2 genes, which play an important role in gut immunity; and Oehlers et al. (2010b) have examined Cxcl8 signaling, which is associated with gut inflammation.

\section{Conclusions}

In summary, zebrafish can be a valuable tool to increase our knowledge of innate immune responses and the regulation of inflammation. The use of genetic and compound screens should help to identify new pathways involved in inflammation resolution and also new compounds to modify these pathways.

\section{Acknowledgements}

We want to thank the funding from the project CSD2007-00002 "Aquagenomics" of the program Consolider-Ingenio 2010 from the Spanish Ministerio de Ciencia e Innovación.

\section{References}

Aggad, D., Stein, C., Sieger, D., Mazel, M., Boudinot, P., Herbomel, P., Lutfalla, G. and Leptin, M. (2010) In vivo analysis of Ifn- $\gamma 1$ and Ifn- $\gamma 2$ signaling in zebrafish. J. Immunol. 185, 6774-6782 
Arslanova, D., Yang, T., Xu, X., Wong, S.T., Augelli-Szafran, C.E. and Xia, W. (2010) Phenotypic analysis of images of zebrafish treated with Alzheimer's gamma-secretase inhibitors. BMC Biotechnol. 10, 24

Balla, K.M., Lugo-Villarino, G., Spitsbergen, J.M., Stachura, D.L., Hu, Y., Bañuelos, K., Romo-Fewell, O., Aroian, R.V. and Traver, D. (2010) Eosinophils in the zebrafish: prospective isolation, characterization, and eosinophilia induction by helminth determinants. Blood 116, 3944-3954

Bates, J.M., Akerlund, J., Mittge, E. and Guillemin, K. (2007) Intestinal alkaline phosphatase detoxifies lipopolysaccharide and prevents inflammation in zebrafish in response to the gut microbiota. Cell Host Microbe 2, 371-382

Bertrand, J.Y., Kim, A.D., Violette, E. P., Stachura, D.L., Cisson, J.L. and Traver, D. (2007) Definitive hematopoiesis initiates through a committed erythromyeloid progenitor in the zebrafish embryo. Development 134, 4147-4156

Bowman, T.V. and Zon, L.I. (2010) Swimming into the future of drug discovery: in vivo chemical screens in zebrafish. ACS Chem. Biol. 5, 159-161

Brugman, S., Liu, K., Lindenbergh-Kortleve, D., Samsom, J.N., Furuta, G.T., Renshaw, S.A., Willemsen, R. and Nieuwenhuis, E.E. (2009) Oxazolone-induced enterocolitis in zebrafish depends on the composition of the intestinal microbiota. Gastroenterology 137, 1757-1767

Buckley, C.E., Marguerie, A., Roach, A.G., Goldsmith, P., Fleming, A., Alderton, W.K. and Franklin, R.J. (2010) Drug reprofiling using zebrafish identifies novel compounds with potential pro-myelination effects. Neuropharmacology 59, 149-159

Carradice, D. and Lieschke, G.J. (2008) Zebrafish in hematology: sushi or science? Blood 111, $3331-3342$

Chang, M.X. and Nie, P. (2008) RNAi suppression of zebrafish peptidoglycan recognition protein 6 (zfPGRP6) mediated differentially expressed genes involved in Toll-like receptor signaling pathway and caused increased susceptibility to Flavobacterium columnare. Vet. Immunol. Immunop. 124, 295-301

Chang, M.X., Nie, P. and Wei, L.L. (2007) Short and long peptidoglycan recognition proteins (PGRPs) in zebrafish, with findings of multiple PGRP homologs in teleost fish. Mol. Immunol. 44, 3005-3023

Chao, C.C., Hsu, P.C., Jen, C.F., Chen, I.H., Wang, C.H., Chan, H.C., Tsai, P.W., Tung, K.C., Wang, C.H., Lan, C.Y. and Chuang, Y.J. (2010) Zebrafish as a model host for Candida albicans infection. Infect. Immun. 78, 2512-2521 
Cheesman, S.E., Neal, J.T., Mittge, E., Seredick, B.M. and Guillemin, K. (2010) Microbes and Health Sackler Colloquium: Epithelial cell proliferation in the developing zebrafish intestine is regulated by the Wnt pathway and microbial signaling via Myd88. Proc. Natl. Acad. Sci. USA. Epub ahead of print

Dahm, R. and Geisler, R. Learning from small fry: the zebrafish as a genetic model organism for aquaculture fish species. Mar. Biotechnol. 8, 329-345

Davidson, A.J. and Zon, L.I. (2004) The 'definitive' (and 'primitive') guide to zebrafish hematopoiesis. Oncogene 23, 7233-7246

Davis, J.M., Clay, H., Lewis, J.L., Ghori, N., Herbomel, P. and Ramakrishnan, L. (2002) Realtime visualization of mycobacterium-macrophage interactions leading to initiation of granuloma formation in zebrafish embryos. Immunity 17, 693-702

de Jong, J.L. and Zon, L.I. (2005) Use of the zebrafish system to study primitive and definitive hematopoiesis. Annu. Rev. Genet. 39, 481-501

Deiters, A. and Yoder, J.A. (2006) Conditional transgene and gene targeting methodologies in zebrafish. Zebrafish 3, 415-429

Dios, S., Romero, A., Chamorro, R., Figueras, A. and Novoa, B. (2010) Effect of the temperature during antiviral immune response ontogeny in teleosts. Fish Shellfish Immunol. 29, 1019-1027

Dobrovolskaia, M.A., Medvedev, A.E., Thomas, K.E., Cuesta, N., Toshchakov, V., Ren, T., Cody, M.J., Michalek, S.M., Rice, N.R. and Vogel, S.N. (2003) Induction of in vitro reprogramming by Toll-like receptor (TLR) 2 and TLR4 agonists in murine macrophages: effects of TLR "homotolerance" versus "heterotolerance" on NF-kappa B signaling pathway components. J. Immunol. 170, 508-519

Dobson, J.T., Seibert, J., Teh, E.M., Da'as, S., Fraser, R.B., Paw, B.H., Lin, T.J. and Berman, J.N. (2008) Carboxypeptidase A5 identifies a novel mast cell lineage in the zebrafish providing new insight into mast cell fate determination. Blood 112, 2969-2972

Dooley, K. and Zon, L.I. (2000) Zebrafish: a model system for the study of human disease. Curr. Opin. Genet. Dev. 10, 252-256

Driever, W. and Fishman, M.C. (1996) The zebrafish: heritable disorders in transparent embryos. J. Clin. Invest. 97, 1788-1794

Du Pasquier, L. (2000) The phylogenetic origin of antigen-specific receptors. Curr. Top. Microbiol. Immunol. 248, 160-185 
Dzhagalov, I., St John, A. and He, Y. (2007) The antiapoptotic protein Mcl-1 is essential for the survival of neutrophils but not macrophages. Blood 109, 1620-1626

Ellett, F., Pase, L., Hayman, J.W., Andrianopoulos, A. and Lieschke, G.J. (2010) mpeg1 promoter transgenes direct macrophage-lineage expression in zebrafish. Blood. Epub ahead of print

Fleming, A., Jankowski, J. and Goldsmith, P. (2010) In vivo analysis of gut function and disease changes in a zebrafish larvae model of inflammatory bowel disease: a feasibility study. Inflamm. Bowel Dis. 16, 1162-1172

Flores, M.V., Crawford, K.C., Pullin, L.M., Hall, C.J., Crosier, K.E. and Crosier, P.S. (2010) Dual oxidase in the intestinal epithelium of zebrafish larvae has anti-bacterial properties. Biochem. Biophys. Res. Commun. 400, 164-168

Flores, M.V., Hall, C.J., Davidson, A.J., Singh, P.P., Mahagaonkar, A.A., Zon, L.I., Crosier, K.E. and Crosier, P.S. (2008) Intestinal differentiation in zebrafish requires $\mathrm{Cdx} 1 \mathrm{~b}$, a functional equivalent of mammalian Cdx2. Gastroenterology 135, 1665-1675

Friedrichs, F., Zugck, C., Rauch, G.J., Ivandic, B., Weichenhan, D., Müller-Bardorff, M., Meder, M., Eddine El Mokhtari, N., Regitz-Zagrosek, V., Hetzer, R., Schäfer, A., Schreiber, S., Chen, J., Neuhaus, I., Ji, R., Siemers, N.O., Frey, N., Rottbauer, W., Katus, H.A. and Stoll, M. (2009) HBEGF, SRA1, and IK: Three cosegregating genes as determinants of cardiomyopathy. Genome Res. 19, 395-403

Hall, C., Flores, M.V., Storm, T., Crosier, K. and Crosier, P. (2007) The zebrafish lysozyme C promoter drives myeloid-specific expression in transgenic fish. BMC Dev. Biol. 7, 42

Hama, K., Provost, E., Baranowski, T.C., Rubinstein, A.L., Anderson, J.L., Leach, S. D. and Farber, S.A. (2008) In vivo imaging of zebrafish digestive organ function using multiple quenched fluorescent reporters. Am. J. Physiol. Gastrointest. Liver Physiol. 296, G445G453

Haslett, C. (1999) Granulocyte apoptosis and its role in the resolution and control of lung inflammation. Am. J. Respir. Crit. Care Med. 160, S5-11

Hegedus, Z., Zakrzewska, A., Agoston, V.C., Ordas, A., Rácz, P., Mink, M., Spaink, H.P. and Meijer, A.H.. (2009) Deep sequencing of the zebrafish transcriptome response to mycobacterium infection. Mol. Immunol. 46, 2918-2930

Herbomel, P., Thisse, B. and Thisse, C. (1999) Ontogeny and behaviour of early macrophages in the zebrafish embryo. Development, 126, 3735-3745 
Herbomel, P., Thisse, B. and Thisse, C. (2001) Zebrafish early macrophages colonize cephalic mesenchyme and developing brain, retina, and epidermis through a M-CSF receptordependent invasive process. Dev. Biol. 238, 274-288

Hortopan, G.A., Dinday, M.T. and Baraban, S.C. Zebrafish as a model for studying genetic aspects of epilepsy. Dis. Model. Mech. 3, 144-148

Hsieh, J., Pan, C. and Chen, J. (2010) Tilapia hepcidin (TH)2-3 as a transgene in transgenic fish enhances resistance to Vibrio vulnificus infection and causes variations in immune-related genes after infection by different bacterial species. Fish Shellfish Immunol. 29, 430-439

Jackson, A.N., McLure, C.A., Dawkins, R.L. and Keating, P.J. (2007) Mannose binding lectin (MBL) copy number polymorphism in Zebrafish (D. rerio) and identification of haplotypes resistant to L. anguillarum. Immunogenetics 59, 861-872

Jault, C., Pichon, L. and Chluba, J. (2004) Toll-like receptor gene family and TIR-domain adapters in Danio rerio. Mol. Immunol. 40, 759-771

Jima, D.D., Shah, R.N., Orcutt, T.M., Joshi, D., Law, J.M., Litman, G.W., Trede, N.S. and Yoder, J.A. (2009) Enhanced transcription of complement and coagulation genes in the absence of adaptive immunity. Mol. Immunol. 46, 1505-1516

Kanther, M. and Rawls, J.F. (2010) Host-microbe interactions in the developing zebrafish. Curr. Opin. Immunol. 22, 10-19

Kaser, A., Zeissig, S. and Blumberg, R.S. (2010) Inflammatory bowel disease. Annu. Rev. Immunol. 28, 573-621

Kizy, A.E. and Neely, M.N. (2009) First Streptococcus pyogenes signature-tagged mutagenesis screen identifies novel virulence determinants. Infect. Immun. 77, 1854-1865

Knapik, E.W. (2000) ENU mutagenesis in zebrafish--from genes to complex diseases. Mamm Genome 11, 511-519

LaPatra, S.E., Barone, L., Jones, G.R. and Zon, L.I. (2000) Effects of infectious hematopoietic necrosis virus and infectious pancreatic necrosis virus infection on hematopoietic precursors of the zebrafish. Blood Cells Mol. Dis. 26, 445-452

Lam, S.H., Chua, H.L., Gong, Z., Lam, T.J. and Sin, Y.M. (2004) Development and maturation of the immune system in zebrafish, Danio rerio: a gene expression profiling, in situ hybridization and immunological study. Dev. Comp. Immunol. 28, 9-28

Langenau, D.M. and Zon, L.I. (2005) The zebrafish: a new model of T-cell and thymic development. Nat. Rev. Immunol. 5, 307-317 
Le Guyader, D., Redd, M.J., Colucci-Guyon, E., Murayama, E., Kissa, K., Briolat, V., Mordelet, E., Zapata, A., Shinomiya, H., and Herbomel, P. (2008) Origins and unconventional behavior of neutrophils in developing zebrafish. Blood 111, 132-141

Lepiller, S., Laurens, V., Bouchot, A., Herbomel, P., Solary, E., Chluba, J. (2007) Imaging of nitric oxide in a living vertebrate using a diamino-fluorescein probe. Free Radic. Biol. Med. 43, 619-627

Levraud, J., Colucci-Guyon, E., Redd, M.J., Lutfalla, G. and Herbomel, P. (2008) In vivo analysis of zebrafish innate immunity. Methods Mol. Biol. 415, 337-363

Li, X., Wang, S., Qi, J., Echtenkamp, S.F., Chatterjee, R., Wang, M., Boons, G.J., Dziarski, R. and Gupta, D. (2007) Zebrafish peptidoglycan recognition proteins are bactericidal amidases essential for defense against bacterial infections. Immunity 27, 518-529

Lieschke, G.J., Oates, A.C., Crowhurst, M.O., Ward, A.C. and Layton, J.E. (2001) Morphologic and functional characterization of granulocytes and macrophages in embryonic and adult zebrafish. Blood 98, 3087-3096

Lieschke, G.J., Oates, A.C., Paw, B.H., Thompson, M.A., Hall, N.E., Ward, A.C., Ho, R.K., Zon, L.I. and Layton, J.E. (2002) Zebrafish SPI-1 (PU.1) marks a site of myeloid development independent of primitive erythropoiesis: implications for axial patterning. Dev. Biol. 246(2), 274-295

Lieschke, G.J. and Currie, P.D. (2007) Animal models of human disease: zebrafish swim into view. Nat. Rev. Genet. 8, 353-367

Lin, B., Chen, S., Cao, Z., Lin, Y., Mo, D., Zhang, H., Gu, J., Dong, M., Liu, Z. and Xu, A. (2007) Acute phase response in zebrafish upon Aeromonas salmonicida and Staphylococcus aureus infection: striking similarities and obvious differences with mammals. Mol. Immunol. 44, 295-301

Liu, F. and Wen, Z. (2002) Cloning and expression pattern of the lysozyme C gene in zebrafish. Mech. Dev. 113, 69-72

Locksley, R.M., Killeen, N. and Lenardo, M.J. (2001) The TNF and TNF receptor superfamilies: integrating mammalian biology. Cell 104, 487-501

Lu, M., Chao, Y., Guo, T., Santi, N., Evensen, O., Kasani, S.K., Hong, J.R. and Wu, J.L. (2008) The interferon response is involved in nervous necrosis virus acute and persistent infection in zebrafish infection model. Mol. Immunol. 45, 1146-1152

López-Muñoz, A., Roca, F.J., Sepulcre, M.P., Meseguer, J. and Mulero, V. (2010) Zebrafish larvae are unable to mount a protective antiviral response against waterborne infection by spring viremia of carp virus. Dev. Comp. Immunol. 34, 546-552 
Maisch, B., Richter, A., Sandmöller, A., Portig, I. and Pankuweit, S. (2005) Inflammatory dilated cardiomyopathy (DCMI). Herz 30, 535-544

Martin, J.S. and Renshaw, S.A. (2009) Using in vivo zebrafish models to understand the biochemical basis of neutrophilic respiratory disease. Biochem. Soc. Trans. 37, 830-837

Mathias, J.R., Perrin, B.J., Liu, T., Kanki, J., Look, A.T. and Huttenlocher, A. (2006) Resolution of inflammation by retrograde chemotaxis of neutrophils in transgenic zebrafish. J. Leukoc. Biol. 80, 1281-1288

Mathias, J.R., Dodd, M.E., Walters, K.B., Rhodes, J., Kanki, J.P., Look, A.T. and Huttenlocher, A. (2007) Live imaging of chronic inflammation caused by mutation of zebrafish Hai1. $J$. Cell Sci. 120, 3372-3383

Mathias, J.R., Dodd, M.E., Walters, K.B., Yoo, S.K., Ranheim, E.A. and Huttenlocher, A. (2009) Characterization of zebrafish larval inflammatory macrophages. Dev. Comp. Immunol. 33, 1212-1217

Meijer, A.H., Gabby Krens, S.F., Medina Rodriguez, I.A., He, S., Bitter, W., Ewa SnaarJagalska, B. and Spaink, H.P. (2004) Expression analysis of the Toll-like receptor and TIR domain adaptor families of zebrafish. Mol. Immunol. 40, 773-783

Meijer, A.H., van der Sar, A.M., Cunha, C., Lamers, G.E., Laplante, M.A., Kikuta, H., Bitter, W., Becker, T.S. and Spaink, H.P. (2008) Identification and real-time imaging of a mycexpressing neutrophil population involved in inflammation and mycobacterial granuloma formation in zebrafish. Dev. Comp. Immunol. 32, 36-49

Moon, H., Jacobson, E.M., Khersonsky, S.M., Luzung, M.R., Walsh, D.P., Xiong, W., Lee, J.W., Parikh, P.B., Lam, J.C., Kang, T.W., Rosania, G.R., Schier, A.F. and Chang, Y.T. (2002) A novel microtubule destabilizing entity from orthogonal synthesis of triazine library and zebrafish embryo screening. J. Am. Chem. Soc. 124, 11608-11609

Neely, M.N., Pfeifer, J.D. and Caparon, M. (2002) Streptococcus-zebrafish model of bacterial pathogenesis. Infect. Immun. 70, 3904-3914

Ng, A.N., de Jong-Curtain, T.A., Mawdsley, D.J., White, S.J., Shin, J., Appel, B., Dong, P.D., Stainier, D.Y. and Heath, J.K. (2005) Formation of the digestive system in zebrafish: III. Intestinal epithelium morphogenesis. Dev. Biol. 286, 114-135

Novoa, B., Romero, A., Mulero, V., Rodríguez, I., Fernández, I. and Figueras, A. (2006) Zebrafish (Danio rerio) as a model for the study of vaccination against viral haemorrhagic septicemia virus (VHSV). Vaccine 24, 5806-5816 
Novoa, B., Bowman, T.V., Zon, L. and Figueras, A. (2009) LPS response and tolerance in the zebrafish (Danio rerio). Fish Shellfish Immunol. 26, 326-331

O'Toole, R., Von Hofsten, J., Rosqvist, R., Olsson, P. and Wolf-Watz, H. (2004) Visualisation of zebrafish infection by GFP-labelled Vibrio anguillarum. Microb. Pathog. 37, 41-46

Oehlers, S.H., Flores, M.V., Chen, T., Hall, C.J., Crosier, K.E. and Crosier, P.S. (2010a) Topographical distribution of antimicrobial genes in the zebrafish intestine. Dev. Comp. Immunol. doi: 10.1016/j.dci.2010.11.008

Oehlers, S.H., Flores, M. V., Hall, C.J., O'Toole, R., Swift, S., Crosier, K.E. and Crosier, P.S. (2010b) Expression of zebrafish cxcl8 (interleukin-8) and its receptors during development and in response to immune stimulation. Dev. Comp. Immunol. 34, 352-359

Ordas, A., Hegedus, Z., Henkel, C.V., Stockhammer, O.W., Butler, D., Jansen, H.J., Racz, P., Mink, M., Spaink, H.P. and Meijer, A.H (2010) Deep sequencing of the innate immune transcriptomic response of zebrafish embryos to Salmonella infection. Fish Shellfish Immunol. doi: 10.1016/j.fsi.2010.08.022

Paik, E.J., de Jong, J.L., Pugach, E., Opara, P. and Zon, L.I. (2010) A chemical genetic screen in zebrafish for pathways interacting with cdx4 in primitive hematopoiesis. Zebrafish 7 , 61-68

Patton, E.E. and Zon, L.I. (2001) The art and design of genetic screens: zebrafish. Nat. Rev. Genet. 2, 956-66

Peng, K., Pan, C., Chou, H. and Chen, J. (2010) Using an improved Tol2 transposon system to produce transgenic zebrafish with epinecidin-1 which enhanced resistance to bacterial infection. Fish Shellfish Immunol 28, 905-917

Petrie-Hanson, L., Hohn, C. and Hanson, L. (2009) Characterization of rag1 mutant zebrafish leukocytes. BMC Immunol. 10, 8

Pham, L.N., Kanther, M., Semova, I. and Rawls, J.F. (2008) Methods for generating and colonizing gnotobiotic zebrafish. Nat. protoc. 3, 1862-1875

Phelps, H.A., Runft, D.L. and Neely, M.N. (2009) Adult zebrafish model of streptococcal infection. Curr. Protoc. Microbiol. Chapter 9, Unit 9D.1

Poorten, T.J. and Kuhn, R.E. (2009) Maternal transfer of antibodies to eggs in Xenopus laevis. Dev. Comp. Immunol. 33, 171-175

Power, M.R., Peng, Y., Maydanski, E., Marshall, J.S. and Lin, T. (2004) The development of early host response to Pseudomonas aeruginosa lung infection is critically dependent on myeloid differentiation factor 88 in mice. J. Biol. Chem. 279, 49315-49322 
Purcell, M.K., Smith, K.D., Hood, L., Winton, J.R. and Roach, J.C. (2006) Conservation of Toll-Like Receptor Signaling Pathways in Teleost Fish. Comp. Biochem. Physiol. Part D $1,77-88$

Rawls, J.F., Samuel, B.S. and Gordon, J.I. (2004) Gnotobiotic zebrafish reveal evolutionarily conserved responses to the gut microbiota. Proc. Natl. Acad. Sci. USA. 101, 4596-4601

Rawls, J.F., Mahowald, M.A., Goodman, A.L., Trent, C.M. and Gordon, J.I. (2007) In vivo imaging and genetic analysis link bacterial motility and symbiosis in the zebrafish gut. Proc. Natl. Acad. Sci. USA. 104, 7622-7627

Redd, M.J., Kelly, G., Dunn, G., Way, M. and Martin, P. (2006) Imaging macrophage chemotaxis in vivo: studies of microtubule function in zebrafish wound inflammation. Cell. Motil. Cytoskeleton. 63, 415-422

Renshaw, S.A., Loynes, C.A., Trushell, D.M., Elworthy, S., Ingham, P.W. and Whyte, M.K. (2006) A transgenic zebrafish model of neutrophilic inflammation. Blood 108, 3976-3978

Renshaw, S.A., Loynes, C.A., Elworthy, S., Ingham, P.W. and Whyte, M.K. (2007) Modeling inflammation in the zebrafish: how a fish can help us understand lung disease. Exp. Lung. Res. 33, 549-554

Rodríguez, I., Novoa, B. and Figueras, A. (2008) Immune response of zebrafish (Danio rerio) against a newly isolated bacterial pathogen Aeromonas hydrophila. Fish Shellfish Immunol. 25, 239-249

Sanders, G.E., Batts, W.N. and Winton, J.R. (2003) Susceptibility of zebrafish (Danio rerio) to a model pathogen, spring viremia of carp virus. Comp. Med. 53, 514-521

Schoonheim, P.J., Chatzopoulou, A. and Schaaf, M.J. (2010) The zebrafish as an in vivo model system for glucocorticoid resistance. Steroids 75, 918-925

Sepulcre, M.P., Alcaraz-Pérez, F., López-Muñoz, A., Roca, F.J., Meseguer, J., Cayuela, M. L. and Mulero, V. (2009) Evolution of lipopolysaccharide (LPS) recognition and signaling: fish TLR4 does not recognize LPS and negatively regulates NF-kappaB activation. $J$. Immunol. 182, 1836-1845

Sieger, D., Stein, C., Neifer, D., van der Sar, A.M. and Leptin, M. (2009) The role of gamma interferon in innate immunity in the zebrafish embryo. Dis. Model. Mech. 2, 571-581

Singer, J.T., Phennicie, R.T., Sullivan, M.J., Porter, L.A., Shaffer, V.J. and Kim, C.H. (2010) Broad-host-range Plasmids for Red Fluorescent Protein Labeling of Gram-negative Bacteria for Use in the Zebrafish Model System. Appl. Environ. Microbiol. 76, 3467-3474 
Solnica-Krezel, L., Schier, A.F. and Driever, W. (1994) Efficient recovery of ENU-induced mutations from the zebrafish germline. Genetics 136, 1401-1420

Stein, C., Caccamo, M., Laird, G. and Leptin, M. (2007) Conservation and divergence of gene families encoding components of innate immune response systems in zebrafish. Genome Biol. 8, R251

Stern, H.M. and Zon, L.I. (2003) Cancer genetics and drug discovery in the zebrafish. Nat. Rev. Cancer 3, 533-539

Stockhammer, O.W., Zakrzewska, A., Hegedûs, Z., Spaink, H.P. and Meijer, A.H. (2009) Transcriptome profiling and functional analyses of the zebrafish embryonic innate immune response to Salmonella infection. J. Immunol. 182, 5641-5653

Streisinger, G., Walker, C., Dower, N., Knauber, D. and Singer, F. (1981) Production of clones of homozygous diploid zebra fish (Brachydanio rerio). Nature 291, 293-296

Su, F., Juarez, M.A., Cooke, C.L., Lapointe, L., Shavit, J.A., Yamaoka, J.S. and Lyons, S.E. (2007) Differential regulation of primitive myelopoiesis in the zebrafish by Spi-1/Pu.1 and C/ebp1. Zebrafish 4, 187-199

Sullivan, C. and Kim, C. H. (2008) Zebrafish as a model for infectious disease and immune function. Fish Shellfish Immunol. 25, 341-50

Sullivan, C., Charette, J., Catchen, J., Lage, C.R., Giasson, G., Postlethwait, J.H., Millard, P.J. and Kim, C.H. (2009) The gene history of zebrafish tlr4a and tlr4b is predictive of their divergent functions. J. Immunol. 183, 5896-5908

Sun, G., Li, H., Wang, Y., Zhang, B. and Zhang, S. (2010) Zebrafish complement factor H and its related genes: identification, evolution, and expression. Funct. Integr. Genomics 10, $577-587$

Swaim, L.E., Connolly, L.E., Volkman, H.E., Humbert, O., Born, D.E. and Ramakrishnan, L. (2006) Mycobacterium marinum infection of adult zebrafish causes caseating granulomatous tuberculosis and is moderated by adaptive immunity. Infect. Immun. 74, 6108-6117

Takeda, N. (2003) Cardiomyopathy: molecular and immunological aspects (review). Int. J. Mol. Med. 11, 13-16

Towbin, J.A. and Bowles, N.E. (2006) Dilated cardiomyopathy: a tale of cytoskeletal proteins and beyond. J. Cardiovasc. Electr. 17, 919-926 
Traver, D., Herbomel, P., Patton, E.E., Murphey, R.D., Yoder, J.A., Litman, G.W., Catic, A., Amemiya, C.T., Zon, L.I. and Trede, N.S. (2003) The zebrafish as a model organism to study development of the immune system. Adv. Immunol. 81, 253-330

Trede, N.S. and Zon, L.I. (1998) Development of T-cells during fish embryogenesis. Dev. Comp. Immunol. 22, 253-263

Trede, N.S., Zapata, A. and Zon, L.I. (2001) Fishing for lymphoid genes. Trends Immunol. 22, 302-307

Trede, N.S., Langenau, D.M., Traver, D., Look, A.T. and Zon, L.I. (2004) The use of zebrafish to understand immunity. Immunity 20, 367-379

Triantafilou, M., Lepper, P.M., Briault, C.D., Ahmed, M.A.E. and Dmochowski, J.M. (2008) Chemokine receptor 4 (CXCR4) is part of the lipopolysaccharide sensing apparatus. Eur. J. Immunol. 38, 192-203

van der Sar, A.M., Musters, R.J., Van Eeden, F.J., Appelmelk, B.J., Vandenbroucke-Grauls, C.M. and Bitter,W. (2003) Zebrafish embryos as a model host for the real time analysis of Salmonella typhimurium infections. Cell. Immunol. 5, 601-611

van der Sar, A.M., Appelmelk, B.J., Vandenbroucke-Grauls, C.M. and Bitter, W. (2004) A star with stripes: zebrafish as an infection model. Trends Microbiol. 12, 451-457

van der Sar, A.M., Spaink, H.P., Zakrzewska, A., Bitter, W. and Meijer, A.H. (2009) Specificity of the zebrafish host transcriptome response to acute and chronic mycobacterial infection and the role of innate and adaptive immune components. Mol. Immunol. 46, $2317-2332$

Venkatesh, B. (2003) Evolution and diversity of fish genomes. Curr. Opin. Genet. Dev. 13, 588-592

Vojtech, L.N., Sanders, G.E., Conway, C., Ostland,V. and Hansen, J.D. (2009) Host immune response and acute disease in a zebrafish model of Francisella pathogenesis. Infect. Immun. 77, 914-925

Volff, J. (2005) Genome evolution and biodiversity in teleost fish. Heredity 94, 280-294

Walters, K.B., Dodd, M.E., Mathias, J.R., Gallagher, A.J., Bennin, D.A., Rhodes, J., Kanki, J.P., Look, A.T., Grinblat, Y. and Huttenlocher, A. (2009) Muscle degeneration and leukocyte infiltration caused by mutation of zebrafish Fad24. Dev. Dyn. 238, 86-99

Walters, K.B., Green, J.M., Surfus, J.C., Yoo, S.K. and Huttenlocher, A. (2010) Live imaging of neutrophil motility in a zebrafish model of WHIM syndrome. Blood 116, 2803-2811 
Wang, Z., Zhang, S., Wang, G., and An, Y. (2008a) Complement activity in the egg cytosol of zebrafish Danio rerio: evidence for the defense role of maternal complement components. PLoS ONE 3, e1463

Wang, Z., Zhang, S., and Wang, G. (2008b) Response of complement expression to challenge with lipopolysaccharide in embryos/larvae of zebrafish Danio rerio: acquisition of immunocompetent complement. Fish Shellfish Immunol. 25, 264-270

Wang, Z., Zhang, S., Tong, Z., Li, L., and Wang, G. (2009) Maternal transfer and protective role of the alternative complement components in zebrafish Danio rerio. PLoS ONE 4, e4498

Wang, C., Tao, W., Wang, Y., Bikow, J., Lu, B., Keating, A., Verma, S., Parker, T.G., Han, R. and Wen, X.Y. (2010) Rosuvastatin, identified from a zebrafish chemical genetic screen for antiangiogenic compounds, suppresses the growth of prostate cancer. Eur. Urol. 58, $418-426$

West, M.A. and Heagy, W. (2002) Endotoxin tolerance: A review. Crit. Care Med. 30, S64$\mathrm{S} 73$

Wienholds, E., Schulte-Merker, S., Walderich, B. and Plasterk, R.H. (2002) Target-selected inactivation of the zebrafish rag1 gene. Science 297, 99-102

Willett, C.E., Cortes, A., Zuasti, A. and Zapata, A.G. (1999) Early hematopoiesis and developing lymphoid organs in the zebrafish. Dev. Dyn. 214, 323-336

Willett, C. E., Zapata, A. G., Hopkins, N. and Steiner, L.A. (1997) Expression of zebrafish rag genes during early development identifies the thymus. Dev. Biol. 182, 331-341

Wu, Z., Zhang, W., Lu, Y. and Lu, C. (2010) Transcriptome profiling of zebrafish infected with Streptococcus suis. Microb. Pathog. 48, 178-187

Xu, Z., Li, Y., Xiang, Q., Pei, Z., Liu, X., Lu, B., et al. (2010) Design and synthesis of novel xyloketal derivatives and their vasorelaxing activities in rat thoracic aorta and angiogenic activities in zebrafish angiogenesis Screen. J. Med. Chem. 53, 4642-4653

Yazawa, R., Hirono, I. and Aoki, T. (2006) Transgenic zebrafish expressing chicken lysozyme show resistance against bacterial diseases. Transgenic Res. 15, 385-391

Yoder, J.A. (2009) Form, function and phylogenetics of NITRs in bony fish. Dev. Comp. Immunol. 33, 135-144

Yoder, J.A., Mueller, M.G., Wei, S., Corliss, B.C., Prather, D. M., Willis, T., Litman R.T., Djeu J.Y. and Litman G.W. (2001) Immune-type receptor genes in zebrafish share genetic 
and functional properties with genes encoded by the mammalian leukocyte receptor cluster. Proc. Natl. Acad. Sci. USA 98, 6771-6776

Yoder, J.A., Nielsen, M.E., Amemiya, C.T., and Litman, G.W. (2002) Zebrafish as an immunological model system. Microb. Infect. 4, 1469-1478

Yoo, S.K., Deng, Q., Cavnar, P.J., Wu, Y. I., Hahn, K.M. and Huttenlocher, A. (2010) Differential regulation of protrusion and polarity by PI3K during neutrophil motility in live zebrafish. Dev. Cell 18, 226-236

Zapata, A., Diez, B., Cejalvo, T., Gutiérrez-de Frías, C. and Cortés, A. (2006) Ontogeny of the immune system of fish. Fish Shellfish Immunol. 20, 126-136

Zon, L.I. and Peterson, R.T. (2005) In vivo drug discovery in the zebrafish. Nature Rev. Drug Discov. 4, 35-344

Zou, J., Mercier, C., Koussounadis, A. and Secombes, C. (2007) Discovery of multiple betadefensin like homologues in teleost fish. Mol Immunol. 44, 638-647 